\title{
Amino Acid Pools in Members of the Genus Erwinia Grown in Continuous Culture
}

\author{
By D. PULMAN AND B. JOHNSON \\ Department of Microbiology, The Medical School, The University, \\ Newcastle upon Tyne NE1 7RU
}

(Received 28 April 1978; revised 13 June 1978)

\section{INTRODUCTION}

Intracellular pools of free amino acids within growing bacteria are highly dynamic and bear little relationship to the amino acid composition of cellular proteins. Normally, glutamate is the major component, whilst alanine, aspartate, glycine and proline may be conspicuous; other common amino acids are usually present in trace amounts (Holden, 1962; Tempest et al., 1970). In addition to providing precursors for macromolecular biosynthesis, two possible functions have been ascribed to the amino acid pool, namely storage of carbon and/or nitrogen (Brown \& Stanley, 1972; Johnson \& Ellwood, 1975) and osmoregulation (Tempest et al., 1970; Brown \& Stanley, 1972).

Through the use of the chemostat, the chemical composition and physiological behaviour of micro-organisms is now known to be largely a function of environment (Tempest et al., 1970). This is also true for amino acid pools, and factors which affect pools, both in composition and content, include the nature of the nitrogen source, growth rate, and salinity of the growth medium (Dawson, 1965; Tempest et al., 1970; Brown \& Stanley, 1972; Johnson \& Ellwood, 1975).

The present study was prompted by the previous finding in this laboratory that the phytopathogenic genus Erwinia is heterogenous with respect to the presence and activity of those enzymes [glutamine synthetase (GS), glutamate synthase (GOGAT) and glutamate dehydrogenase (GDH)] which are commonly accepted as being of major importance in bacterial ammonia assimilation (see Pulman \& Johnson, 1975, 1978). Further, in some organisms, e.g. E. amylovora, only GS was detectable which alone cannot account for net assimilation of ammonia. Thus a comparative examination of amino acid pools present in chemostat-grown cultures of representative Erwinia strains might yield useful information pertaining to the mechanisms of ammonia assimilation which operate in this genus.

\section{METHODS}

Bacterial strains and growth. Details of the bacteria used in the present study, and their maintenance, were as previously described (Pulman \& Johnson, 1978). Organisms were grown in a Porton-type chemostat under conditions of either ammonia-limitation (glucose-excess) or ammonia-excess (glucose-limited) as described by Pulman \& Johnson (1978).

Extraction of amino acid pools and amino acid analyses. Samples (equivalent to 100 to $250 \mathrm{mg}$ dry wt bacteria) were harvested direct from the vessel and were immediately centrifuged at $4500 \mathrm{~g}$ for $10 \mathrm{~min}$ at $4{ }^{\circ} \mathrm{C}$. The resulting pellet was suspended in $70 \%(\mathrm{v} / \mathrm{v})$ ethanol for $15 \mathrm{~min}$ at room temperature, with intermittent agitation, to extract free amino acids. (Alternative methods of extraction, such as boiling water, different ethanol concentrations and $0.25 \mathrm{M}-\mathrm{HClO}_{4}$, were less efficient.) The resulting suspension was centrifuged at $4500 \mathrm{~g}$ for $10 \mathrm{~min}$ at $4{ }^{\circ} \mathrm{C}$, and the clear supernatant was reduced to dryness using an 'Evapomix' (Buchler Instruments, Fort Lee, N.J., U.S.A.) at $40^{\circ} \mathrm{C}$ and stored at $-10^{\circ} \mathrm{C}$ until required.

Extracts were dissolved in $0.2 \mathrm{M}$-sodium citrate buffer $(\mathrm{pH} 2.6)$ and analysed using a Technicon automatic amino acid analyser. Samples, together with a known amount of norleucine as internal standard, were applied to a single column $(23 \times 0.5 \mathrm{~cm})$, filled with Technicon $\mathrm{C}-3$ resin $(12 \mu \mathrm{m}$ diam.), the system employing a 


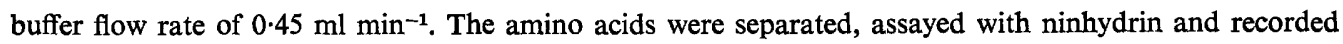
automatically. Estimation and identification of individual amino acids was by comparison with known standards. Some secondary analysis was performed using a Locarte analyser (Locarte, London).

\section{RESULTS}

The composition of amino acid pools isolated from cultures of members of the three clusters recognized within the genus Erwinia, namely the 'amylovora', 'carotovora' and 'herbicola' groups (Lelliott, 1974), are shown in Table 1 . With only one exception, $E$. stewartii, the total pool was greater under conditions of ammonia-excess (glucose-limited) than under those of ammonia-limitation (glucose-excess), although considerable variations were apparent in the magnitude of the difference in pool sizes for individual species and also in the total pool content of different species grown under the same conditions.

Within the 'amylovora' cluster, which is heterogeneous with respect to ammoniaassimilating enzymes (Pulman \& Johnson, 1978), the ammonia-limited pools were very low and similar in all strains examined. The predominant components were glutamate and alanine, whilst the non-separated group of glutamine/serine/threonine was also conspicuous (Table 1). Interestingly, the concentration of arginine was high in those organisms possessing GOGAT (E. quercina, E. rubrifaciens, E. salicis) whilst in E. amylovora, which shows only GS activity, it was low. Upon transfer to glucose-limited conditions, there was a 10-fold increase in the total pool of E. amylovora, glutamate, aspartate, alanine, lysine, glycine and ornithine being largely responsible for the rise. Although pool increases in $E$. quercina, E. rubrifaciens and E. salicis were much lower, the same components were conspicuous. The relatively high concentrations of arginine observed in the latter organisms under ammonia-limited conditions were substantially decreased under conditions of glucose limitation.

Total pools from ammonia-limited cultures of members of the 'carotovora' cluster, also heterogeneous with respect to ammonia-assimilating enzymes (Pulman \& Johnson, 1978), were low and similar to those observed in members of the 'amylovora' cluster (Table 1). Once again, glutamate and alanine were predominant components, whilst $E$. carotovora var. carotovora and E. chrysanthemi (GOGAT-positive) showed high arginine concentrations but in $E$. cypripedii and $E$. rhapontici (GOGAT-negative), the arginine concentrations were low. Transfer of E. carotovora var. carotovora, E. cypripedii and E. rhapontici from ammonia- to glucose-limited conditions resulted in pools which were approximately doubled, the increase being largely accounted for by glutamate, aspartate, alanine, lysine and glycine. In E. chrysanthemi, however, transfer to glucose-limited conditions resulted in a 12-fold increase in pool size, which was almost totally accounted for by glutamate, although a proportional increase was observed in aspartate. The high concentrations of arginine observed in ammonia-limited GOGAT-positive strains were decreased under conditions of glucose-limitation.

Within the 'herbicola' cluster, the examined members of which exhibit only GS activity (Pulman \& Johnson, 1978), total pools extracted from ammonia-limited cultures were again low (Table 1) and consistent with those found in the 'amylovora' and 'carotovora' clusters. Similarly, glutamate and alanine were major components, although E. herbicola var. herbicola, E. stewartii and E. uredovora also showed high concentrations of valine. The content of arginine was low in all strains, this being consistent with the absence of GOGAT activity. Transfer from conditions of ammonia-limitation to those of glucose-limitation caused an approximately fivefold increase in the pools of E. herbicola var. herbicola, $E$. herbicola var. ananas and E. uredovora with typical increases in glutamate, aspartate, alanine and glycine. In contrast, the total amino acid pool of $E$. stewartii altered little in response to transfer from ammonia- to glucose-limited conditions. However, both glutamate and aspartate showed increased concentrations, which were offset by decreases in the concentrations of alanine and valine. 


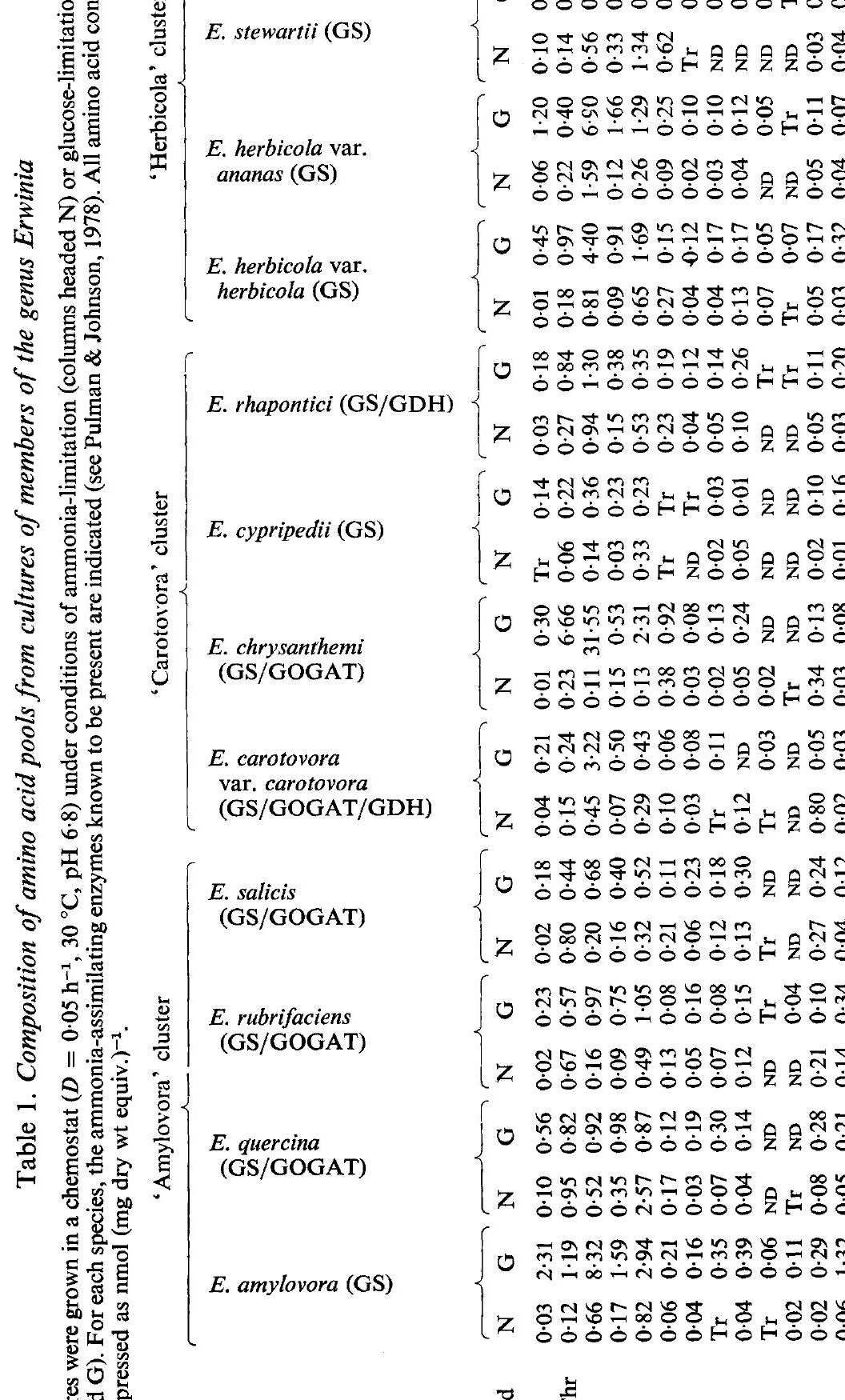




\section{DISCUSSION}

The present study has demonstrated that members of the genus Erwinia contain total free amino acid pools typical of Gram-negative bacteria, in that they are small by comparison with Gram-positive organisms (Tempest et al., 1970). The compositions of pools from Erwinia species are similar to those reported for other Gram-negative bacteria, in that although up to 16 amino acids were usually detectable, the major components were normally glutamate, alanine, aspartate and glycine. Proline was not detected in any of the cultures examined.

The total pools extracted from ammonia-limited cultures of Erwinia species were substantially lower than those reported for other Gram-negative bacteria grown under similar conditions (Tempest et al., 1970), although this can probably be ascribed to the lower growth rate employed in the present study. The increase in pool size observed upon transfer of Erwinia species from conditions of ammonia-limitation to those of ammonia-excess (glucose-limitation) agrees well with the suggestion of Brown \& Stanley (1972) that pools extracted from ammonia-limited bacterial cultures represent the minimum required for growth under the imposed conditions. Although, upon transfer to ammonia-excess conditions, a general increase was observed in most of the pool amino acids, consistently large rises were seen in glutamate, aspartate, glycine and lysine with occasional increases in ornithine. It is possible that such concomitant rises in acidic and basic components might represent an attempt by the cell to maintain electroneutrality. By comparison with other members of the genus examined, E. amylovora and E. chrysanthemi showed particularly large pool increases in response to increased medium ammonia concentration, the reasons for which are not clear.

There was little relationship between the amino acid pools extractable from Erwinia species and the three clusters of the genus recognized by Lelliott (1974) or the ammoniaassimilating enzyme groups defined by Pulman \& Johnson (1978), thereby confirming the rather heterogeneous nature of the genus. In all organisms examined, regardless of their complement of GS/GOGAT/GDH, the predominant pool amino acids of ammonia-limited cultures were similar (principally alanine and glutamate), thus shedding little light on the mechanism whereby those organisms showing only GS activity are able to assimilate ammonia into metabolism. Two features are worthy of further comment. First, the glutamine-containing peak in those organisms showing only GS activity was generally much lower than that seen in other organisms; this might imply that in the former group glutamine still represents an intermediate in ammonia assimilation but that it is utized in some subsequent transfer reaction much more efficiently than in the latter group. Alternatively, an as yet undetected glutamine-independent pathway of ammonia assimilation may operate, in which case GS would fulfil only the role of providing glutamine for the biosynthesis of other biomolecules. Second, all organisms showing GS/GOGAT activity, when grown under conditions of ammonia-limitation, showed a high pool concentration of arginine (although this was much lower under conditions of glucose-limitation). The reasons for this behaviour, which appeared to characterize the presence of GOGAT, are not clear.

This study has confirmed the complexity of the genus Erwinia with respect to ammonia assimilation (see Pulman \& Johnson, 1978), and emphasizes the need for further study of the process in this economically important genus.

We would like to thank Professor D. C. Ellwood, Mr J. R. H. Slade and Mr H. K. Robinson for assistance with amino acid analyses and for helpful discussion. One of us (D.P.) is grateful to the Science Research Council for the award of a postgraduate research studentship. 


\section{REFERENCES}

Brown, C. M. \& Stanley, S. O. (1972). Environment-mediated changes in the cellular content of the 'pool' constituents and their associated changes in cell physiology. Journal of Applied Chemistry and Biotechnology 22, 363-389.

Dawson, P. S. S. (1965). The intracellular amino acid pool of Candida utilis during growth in batch and continuous flow cultures. Biochimica et biophysica acta 111, 51-66.

Holden, J. T. (1962). The composition of microbial amino acid pools. In Amino Acid Pools, pp. 73-108. Edited by J. T. Holden. Amsterdam: Elsevier.

Johnson, B. \& Ellwood, D. C. (1975). The amino acid pool of Hansenula holstii; characterisation and changes mediated by environment. Antonie van Leeuwenhoek 41, 411-419.
Lelliott, R. A. (1974). Erwinia Winslow, Broadhurst, Buchanan, Krumwiede, Rogers and Smith, 1920, 209. In Bergey's Manual of Determinative Bacteriology, 8th edn, pp. 332-340. Edited by R. E. Buchanan \& N. E. Gibbons. Baltimore: Williams \& Wilkins.

Pulman, D. \& Johnson, B. (1975). The enzymes of ammonia assimilation in members of the genus Erwinia. Proceedings of the Society for General Microbiology 3, 55.

Pulman, D. \& Johnson, B. (1978). The enzymes of ammonia assimilation and their control in members of the genus Erwinia. Journal of General Microbiology 106, 137-143.

Tempest, D. W., Meers, J. L. \& Brown, C. M. (1970). Influence of environment on the content and composition of microbial free amino acid pools. Journal of General Microbiology 64, 171-185. 